\title{
Diálogos: Mário de Andrade e os parnasianos
}

Ligia Rivello Baranda Kimori ${ }^{1}$

"Cada arte no seu galho.

Os galhos é verdade entrelaçam-se às vezes"

Mário de Andrade. A escrava que não é Isaura.*

PERCorRer obras PARNASIANAS PELA MÃo do LEITOR ARGUTO MÁRIO DE ANDRADE, POETA E CRÍTICO EM FORMAÇÃO QUE PARA NAS PRÓPRIAS ESTANTES, AMPLIA O CONHECIMENTO DE SUAS FONTES LITERÁRIAS E DE SEU PROCESSO CRIATIVO. Em suas notas nessas obras, resíduo valioso da sua leitura nos 57 títulos parnasianos - de 21 poetas brasileiros e 5 franceses - que compõem sua coleção ${ }^{2}$, expressa, com liberdade, sua captação de aspectos estéticos, estilísticos e técnicos; acata, absorve, avalia e revisita; contesta, discute, rebate e rompe. Guarda movimentos da sua leitura nas etapas que, nos textos fragmentários que constituem sua marginália, se insinuam na letra, no uso dos instrumentos para escrever; testemunhando pesquisas encetadas, interesses dominantes.

O viés da crítica genética fornece subsídios, nesse caso, para refazer percursos da historiografia literária ao lidar com anotações autografas de um leitor interessado que, ao longo da trajetória de escritor, revisita sua coleção de obras parnasianas entre 1914 e 1933. Tal período ultrapassa, e muito, o marco da semana modernista de 1922, testemunhando diálogos entre escolas literárias historicamente contrapostas. A perspectiva ofertada pela correspondência e a marginália implementam um importante capítulo das tensões entre a arte dita passadista e seus antagonistas modernos, intervindo em aspectos consolidados pela crítica.

Há, em registro, duas incursões do leitor Mário nas obras parnasianas que aparecem datadas, ambas no mesmo ano de 1925: em "Jesus entre as crianças" quase dez anos depois, em 24 de setembro; e no elogio repetido a Bilac, aos versos de "Salutaris porta" " "É um dos mais belos sonetos do mundo./20-XI-925”. Esclareço, porém, que existe uma parcela de notas a tinta em Poesias completas $^{5}$, de Machado de Assis, evidenciando incursões iniciais ${ }^{6}$ nessa marginália, sem data. Quanto ao possível período de circulação do leitor entre essas obras, no rodapé do poema "Delenda Carthago!" ${ }^{7}$, também de Bilac, Mário transcreve trecho do estudo A arte de fazer versos, de Osório Duque Estrada, edição de 1914, marcando o tempo de uma leitura primeira, pautada pelo estudo explícito da marginália nos livros de sua coleção, reveladora

\footnotetext{
${ }^{1}$ Doutora em Literatura Brasileira pela Universidade de São Paulo. E-mail: 1ilofr@gmail.com

${ }^{2}$ A maioria dos volumes parnasianos está na Coleção Mário de Andrade, acervo no Instituto de Estudos Brasileiros (IEBUSP); outra parcela, sobretudo os parnasianos franceses, figura entre os livros doados, em 1942, à Biblioteca Pública de Araraquara.

${ }^{3}$ AMARAL, Amadeu. Espumas: versos. São Paulo: Editora d’A Cigarra, 1917, p.61.

${ }^{4}$ BILAC, Olavo. Salutaris porta In: Tarde. Rio de Janeiro/ São Paulo/ Belo Horizonte: Livraria Francisco Alves, 1919 , p.156.

${ }^{5}$ MaCHAdo De Assis. Poesias completas. Rio de Janeiro/ Paris: Livraria Garnier, 1902.

${ }^{6}$ As notas a tinta ligam-se a instantes primeiros da marginália de Mário de Andrade. Para detalhes, V. LOPEZ, Telê Ancona. Mário de Andrade leitor e escritor: matrizes e marginália. Guavira Letras, Três Lagoas/ MS, no 23, p. 14-33, jul/ dez 2016, p. 20-21.

${ }^{7}$ BILAC, Olavo. Poesias. 4a. ed. Rio de Janeiro/ São Paulo/ Belo Horizonte: Livraria Francisco Alves, 1909, p. 35.
} 
da leitura que desperta a poesia no jovem paulistano. O dicionário de Firmino Costa, Vocabulário analógico ${ }^{8}$, em sua primeira edição de 1933, na coleção de Mário de Andrade, mencionado em nota de estudo do poema Marabá, de Martins Fontes, delimita o alcance da leitura anotada descrita nos exemplares.

No entanto, se tomarmos versos d"'A meditação sobre o Tietê”, de Lira Paulistana, concluída nos últimos dias de vida do escritor, em fevereiro de 1945, ainda outras possibilidades se apresentam:

Por que me proíbes assim praias e mar, por que

Me impedes a fama das tempestades do Atlântico

E os lindos versos que falam em partir e nunca mais voltar?

É preciso reparar no último verso. No soneto "Contraditório"10, de Amadeu Amaral, um comentário do leitor indica a apropriação ou emulação de "As pombas", de Raimundo Correia - poeta acusado de plagiar o parnasiano francês Théophile de Gautier na época da publicação. Segue a nota para esclarecer:

Quanta fadiga vã! Quanto tempo perdido!

Como o sonho é enganoso!... Ai de mim! se eu pudesse

partir segunda vez e nunca mais voltar... (1)

Nota MA: De Oscar Lopes há um soneto que termina/ assim: “. Velas ao mar..."/ Vendo-nos o meu ser estranha idea afaga:/ - Ir com aquela de vos que nunca mais voltar!” Não sei qual dos poemas é anterior. Nem mesmo se um dos poetas tenha sentido uma reminiscência da idea do outro. É mais provável que não. A idea nada tem de rara e a mera coincidência de palavras é pouco ou nada condenável num caso dêstes. Depois do "não voltam mais” de Raimundo, o refrão tem sido reproduzido, variado, parafraseado, dum modo desoladoramente monótono por uma grande quantidade de poetas.

Como percebemos, para o crítico-leitor, o cerne da questão é a citação artística com habilidade, a imitação seguida da emulação que ressignifique um paradigma estético. Voltando ao poema de Mário, poeta moderno, sobressai a referência ao poema de Amadeu Amaral ou Raimundo Correia estendendo até sua produção final o contato profícuo com os parnasianos, expresso no verso "Nunca mais voltar".

Assim, o diálogo longevo e vivaz de Mário de Andrade garante o leitor ávido por soluções estéticas, curioso em compreender o alcance das obras, livre para consultar materiais que compõem seu acervo, sem restrição e guiado por seu crivo que, claramente, independe da linha literária.

Recuperar comentários críticos do leitor - elogio e recusa - armazenados nas entrelinhas e rodapés de poemas parnasianos, identificar prototextos de artigos que balizam estratégias modernistas para galgar espaço literário ou colher ecos dessa leitura parnasiana em poemas seus mostram-se tarefas importantes: evidenciam elementos da estética parnasiana possivelmente reduzidos em complexidade em razão da consistente divulgação modernista, restabelecendo o elo entre períodos aparentemente paradoxais, enquanto viabiliza enredamentos importantes.

\footnotetext{
${ }^{8}$ CosTA, Firmino. Vocabulário analógico. São Paulo: Melhoramentos, 1933.

9 Andrade, Mário de. A meditação sobre o Tietê In: Lira Paulistana In: Poesias completas v.1, Op. cit., p. 543. (grifo nosso)

${ }^{10}$ AMARAL, Amadeu. Contraditório In: Espumas: versos. Op. cit., p.86.
} 
O senso de ordem positivista latente nos poemas parnasianos reflete-se na qualidade técnica e, possivelmente, nos cuidados com o primor da linguagem. Arredondando as formas românticas, preferem os versos burilados e repudiam a figura do gênio, reforçando o trabalho de ourives das palavras. Assim, potencializam gradativamente o prestígio da figura do escritor: ocupam espaços cada vez mais sólidos em jornais, fazem circular a poesia em saraus e conferências, instituem a Academia Brasileira de Letras. Como recurso literário, o tom torna-se mais objetivo na substituição dos pronomes pessoais - da primeira pessoa pelas demais -, mas, distante da impassibilidade referida como característica essencial da escola, adotam a sentimentalidade passível de descrição. Dessa forma, quadros descritivos de impecável plasticidade imagética estampam estrofes com rima, métrica e sonoridade bem acabada. As enumerações - de frases, refrões, pares adjetivo-substantivo - encadeiam o ritmo de muitos poemas e, ao lado das citações poéticas (emulação?), tocam outros universos culturais quando homenageiam ou ressignificam obras ${ }^{11}$. Ou seja, esses poetas assimilam processos dos mestres franceses, agregando elementos e situando uma poesia de feição brasileira. O leitor Mário recolhe esses rudimentos. As notas por ele traçadas espelham a passagem do tempo, entre moralistas e técnicas, jocosas ou miméticas, oferecendo estágios de um leitor em formação, retratos de um escritor em seu percurso.

Como exemplo, apresento nota representativa do viés de análise do arguto leitor Mário que examina as obras seguro de aferir com precisão a poesia parnasiana, deleite e análise armazenados. Bem ilustra o envolvimento e o preparo crítico desse leitor o comentário marginal ao poema "A palmeira e o raio", de Amadeu Amaral:

Nota MA: Eis um poema sublime e dos mais perfeitos que a nossa literatura moderna tem produzido. A lingua é prodigiosa; a técnica é poderosa, com um emprego porventura frequente de mais dos entroncamentos; e a idea é admirável, fúlgida e verdadeira. Nada mais lindo que a fala da palmeira. A elasticidade das frases, o brilho das onomatopeas, a certeza dos conceitos fazem desta poesia uma obra inegualável, original, única. O p. dedicando-a a Alberto de Oliveira, recordou-se talvez do quanto se assemelhava na técnica ao autor do Paraíba e da Ode ao Sol. ${ }^{12}$

Decerto, a herança romântica permeia a obra dos parnasianos, sobretudo no que se refere "a emoção sincera dos primeiros tempos e o sentimento da natureza”, como admite Alberto de Oliveira ${ }^{13}$. A marca árcade também transparece, seja na seleção lexical ou na escolha de epítetos. Eugênio Gomes, no denso estudo sobre a poesia dessa geração, discute o tema ao analisar o estilo de Raimundo Correia:

[...] o poeta do "Mal secreto" [...], através de sua linguagem, deu mostras de mais profunda impregnação dos árcades, sem deixar de revelar uma imaginação essencialmente romântica. É o testemunho que se depara em seu rebuscado vocabulário poético, no qual os epítetos de

\footnotetext{
${ }^{11} \mathrm{O}$ estudo detalhado do parnasianismo, com apresentação do contexto histórico e seleção de excertos de poemas pode ser consultado em RAMOS, Péricles Eugênio da Silva. A renovação parnasiana na poesia In: CoutiNHO, Afrânio (Org.). A
}

literatura no Brasil, vol. 4: era realista, era de transição. São Paulo: Global, 2004; SANTIAGO, Emmanuel. A musa de espartilho: o erotismo na poesia parnasiana brasileira. Tese de doutorado sob orientação de Vagner Camilo, FFLCHUSP, 2016; SECCHIN, Antonio Carlos. Presença do Parnaso In: JUNQUEIRA, Ivan (Org.). Escolas literárias no Brasil. Rio de Janeiro: Academia Brasileira de Letras, 2004.

${ }^{12}$ AmARAL, Amadeu. A palmeira e o raio In: Espumas: versos, Op. cit., p. 32.

13 OLIVEIRA, Alberto de. O culto da forma na poesia brasileira In: Conferências 1914-1915. São Paulo: Typographia Levi, 1916, p. 273. Conferência realizada em 10 de novembro de 1915. 
cunho latino, raramente empregados ou já em desuso na época, predominam com expressiva frequencia, imprimindo à sua poesia um tom inteiramente peculiar por esse aspecto. ${ }^{14}$

O gosto pela sonoridade, sensível preferência de Mário leitor, explica, na marginália de Machado, no seu exemplar de Poesias Completas, as sinéreses em desalinho e as licenças poéticas destacadas a grafite:

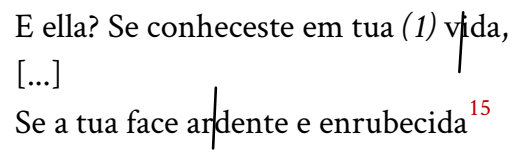

Nota MA: (1) M. d'assis como se vê conta também 2 silabas em tua: tu-a.

12

O alinho gramatical, a escolha de vocábulos raros/ preciosos, a adequação vocabular ("mot juste"), as inversões, relação conteúdo-forma bem resolvida, a concisão, o encadeamento e os enjambements/ entroncamentos participam também da estrutura dos poemas parnasianos. Esse último recurso de composição, trabalhado com destreza pelos poetas da escola, em que os versos não pausam ao final, eliminando a coincidência com a frase, atinge de muitas maneiras o leitor Mário de Andrade. Ele admira esse processo poético em Alberto de Oliveira, por exemplo, no soneto "Floresta convulsa":

\footnotetext{
Floresta de altas árvores, escuta:

Em minha dor vim conversar contigo,

Como no seio do melhor amigo,

Descanso aqui de tormentosa luta.

Troncos da solidão intacta e bruta, Sabei... Ah ! que, porém, como um castigo

Vos estorceis, e o som do que vos digo

Vai morrer longe em solitária gruta.

Que tendes, vegetais?... remorso?... crime?...

Açoita-vos o vento, como um bando

De fúrias e anjos maus, que nós não vemos?

Mas explicai-vos ou primeiro ouvi-me,

Que a um tempo assim braceando, assim gritando,

Assim chorando não nos entendemos ${ }^{16}$.
}

\footnotetext{
${ }^{14}$ GomES, Eugênio. Raimundo Correia e o idealismo horaciano In: Visões e revisões. Rio de Janeiro: Instituto Nacional do Livro, 1958, p. 112.

${ }^{15}$ Machado De Assis. Parte L de Pallida Elvira In: Poesias Completas, Op. cit., p. 157.

${ }^{16}$ Oliveira, Alberto de. Floresta convulsa In: Poesias 3a série (Sol de verão, Céo nocturno, Alma das cousas, Sala de baile, Rimas varias, No seio do cosmos, Natalia). Rio de Janeiro/ São Paulo/ Belo Horizonte: Livraria Francisco Alves e cia, 1913, p. 96.
} 
Nota MA: É dos versos mais perfeitos de Alberto. Notar a naturalidade dessas frases, tão escassa nêle a beleza desses entroncamentos

A familiaridade do leitor com os dispositivos estéticos da poesia parnasiana verifica-se, sobretudo, em notas como essa, de valor qualitativo, quando aplaude êxitos ou repreende determinados usos, estudando a feitura de uma estrofe em que o poeta ensaia adotar uma solução específica.

Os enjambements afinam a relação ritmo e cesura. Característico de composições líricas galego-portuguesa, o recurso é retomado pelos parnasianos como alternativa ao paralelismo tradicional, moldando versos que não dão conta da frase. Com o enjambement, duas possibilidades sonoras se encaixam: a leitura pautada pelo fim do verso, unidade rítmica, e a leitura determinada sintaticamente, oração completa. Preminger e Brogan explicam a diferença:

"In reading, the noncoincidence of the frames of syntax and meter in [enjambement] has the effect of giving the reader 'mixed messages': the closure of the metrical pattern at line-end implies a stop (pause), no matter how infinitesimal, while the obvious incompletion of the syntactic period says, go on. The one scissors the other. These conflicting signals, in heightening readerly tension, also thereby heighten awareness, so that in fact one is made more aware of the word at line-end than its predecessors [...]". ${ }^{17}$

O recurso, conciliando cesura fixa e móvel, carrega marca de modernidade quanto à ideia de verso, pois a unidade de ritmo se desfaz e flexiona modos de leitura de exploração melódica variada. Dentro do conjunto das regras, esse artifício estético interessante angaria comentários do leitor meticuloso, ciente dos procedimentos técnicos.

Outra solução estética, os quadros descritivos, o leitor Mário apreende quando se achega a modelos feito "Ode ao sol", de Alberto de Oliveira, com estrofes que considera sublimes ${ }^{18}$. A descrição, em pormenores, de fino lavor impressionista, recebe traços duplos a grafite:

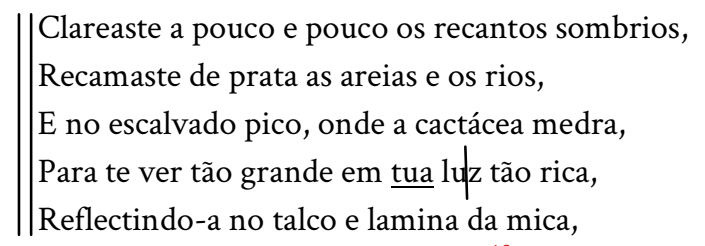

Fizeste o olhar da pedra. ${ }^{19}$

\footnotetext{
${ }^{17}$ Traduzo: "Na leitura, a não coincidência dos quadros de sintaxe e metro em [enjambement] tem o efeito de fornecer ao leitor 'mensagens mistas': o encerramento do padrão métrico no final da linha implica uma parada (pausa), não importa quão infinitesimal, enquanto a óbvia incompletude do período sintático diz, continue. Uma corta a outra. Esses sinais conflitantes, ao aumentar a tensão da leitura, também aumentam a consciência, de modo que, de fato, a pessoa se torna mais consciente da palavra no final da linha do que seus predecessores [...]”. PREMINGER, Alex; BROGAN, T. V. F (Ed.). Enjambement. In: The new princeton encyclopedia of poetry and poetics. Princeton: Princeton University Press, 1993 , p. 359.

${ }^{18}$ Em Poesias (2a série), do mesmo poeta parnasiano, Mário registra o elogio na p. 76, comparando figuras de linguagem: "(1) No "Hino ao sol" - 3a série - A. de Oliveiral se utiliza desta mesma figura e a torna genial em uma daquelas estrofes/ sublimes". Mário engana-se quanto ao título que é "Ode ao Sol”.

${ }^{19}$ OLIVEIRA, Alberto de. Ode ao sol In: Poesias 3a série, Op. cit., p. 20.
} 
O artifício descritivo parnasiano, introduzindo elementos temporais e advérbios de lugar, conectivos, numa estratégia quase narrativa, focaliza a cena/objeto e cumpre a ele transmitir o olhar do poeta. Revela-se uma estética da contemplação, nomeando partes constituintes do quadro escolhido. $O$ jovem leitor, no seu método de cotejo, sabe avaliar e exige de si qualidade na tarefa, como registra no comentário à Parte I de "O Açude" ${ }^{20}$, no livro Espumas de Amadeu Amaral:

Nota MA: O A. não sabe descrever. Não se vê o que ele descreve, não tem como V. de Carvalho, Martins Fontes, Gonçalves Dias, Porto Alegre, Basílio da Gama a genialidade descritiva. É poeta muito de secretária.

Debruçado sobre o matiz lexical desses poetas, consultando os bons dicionários que possui, o leitor familiariza-se com modos de dizer e repara na estrutura sintática particular, buscando os caminhos estilísticos sagrados em tantos versos: arcaísmos e palavras raras ganham-lhe a atenção; pares de adjetivos e anáforas figuram constantemente nos destaques, na marginália. Em seus poemas de juventude, Mário de Andrade esbanja todo o vocabulário armazenado, medindo, em exercício de composição, preferências suas. Assim acontece nestes versos de "Eterno estrondo", guardados em seu arquivo, recorte sem indicação de data ou local de publicação. As quadras do soneto sugerem o gosto pelo vocabulário precioso:

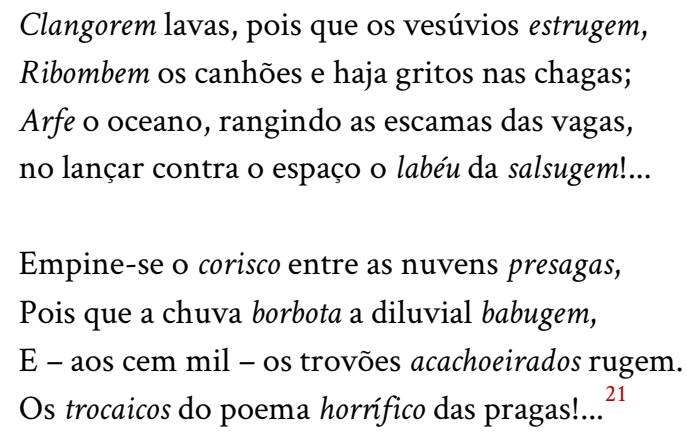

A retomada dos três vetores que compõem o sistema literário proposto por Antonio Candido, "um conjunto de produtores literários, mais ou menos conscientes do seu papel; um conjunto de receptores, formando os diferentes tipos de público, sem os quais a obra não vive; um mecanismo transmissor (de modo geral, uma linguagem, traduzida em estilos), que liga uns a outros ${ }^{22}$, permite afirmar que, no parnasianismo, a literatura brasileira funciona com coerência interna, longe de se caracterizar como refém de influxos externos, como enfatiza o crítico. A dicção de nossos poetas, mestres do verso, encontra esteio próprio e ressoa na produção que se estabelece na sequência, irradiada por significativos prismas. Aspectos dessa poesia acompanham o moderno Mário, não somente em seus poemas da juventude, mas perpassando temas e formas de versar que atingem seus textos da maturidade ${ }^{23}$. O escritor prossegue, em todo seu percurso de formação, pesquisa e criação, trabalhando

\footnotetext{
${ }^{20}$ AMARAL, Amadeu. O açude In: Espumas: versos, Op. cit., p. 124.

${ }^{21}$ ANDRADE, Mário de. Eterno estrondo In: Poesias completas v. 2, Op. cit., p. 132. (grifo nosso)

${ }^{22}$ ANTONIO CANDIDO. Literatura como sistema In: Formação da literatura brasileira. 12a Ed. São Paulo/ Rio de Janeiro: Ouro sobre Azul, 2009, p. 25.

${ }^{23}$ Para acompanhar a latência de temas, termos e construções parnasianas em poemas do modernista, vide KIMORI, Ligia. Pauliceia parnasiana: Mário de Andrade leitor e poeta nas margens de Baptista Cepellos. ELyra: Revista Da Rede
} 
com um variado acervo de princípios estéticos. Palmilha procedimentos do passado e molda o novo, caminha em paralelo imerso em várias instâncias estruturais que guardam a marca do polígrafo. Leitor dos parnasianos brasileiros e franceses, auxiliado por um conhecimento técnico afinado, conhece valores plásticos, formais, sonoros e de composição dessa poesia. A característica polimetria, a previsibilidade de acentuação em determinados casos, a destreza dos versos medidos baralhados no ensaio de versos livres denotam o leitor-poeta cultivado, marcado pela técnica. Na crítica, a análise da cadência e das estruturas também filia o leitor que zela pelo acabamento burilado. Assim, a marginália de Mário de Andrade nas obras do parnasianismo franqueia um diálogo caudaloso e fecundo, na parcela estética que integra a formação do poeta e do crítico moderno.

Após classificação, estudo e análise da marginália nas obras parnasianas, rastreando parte das escolhas formadoras do modernista, fica difícil prosseguir na chave de leitura que interpreta o parnasianismo como uma interrupção na linha literária, sem aderência para as gerações seguintes por configurar mera cópia subalterna de modelos europeus, salvo instantes iluminadores. Preceito crítico reiterado ao longo do tempo, pensar a produção modernista enquanto ruptura total com a arte que a precede, sem examinar os pontos de junção e continuidades estéticas, nega a importância de uma rede de apropriações que nunca cessou.

As vanguardas, transgressão para estabelecimento de outro paradigma estético, mesmo em sua multiplicidade, figuram como campo de observação do alheio, seja através da busca, no exterior, de uma fonte renovadora ou do aprimoramento de instâncias técnicas de um passado mais longínquo, que nega o padrão estilístico imediato - os possíveis profetas atuantes em seu tempo. Em análise alentada, Béatrice Joyeux-Prunel, aproveitando a expressão "Ninguém é profeta em sua própria terra" ${ }^{24}$ - inspirada nos Evangelhos de Marcos e Lucas ao narrar a volta de Jesus à cidade natal de Nazaré -, estuda o impacto das tentativas de mudança e difusão nas artes plásticas, manobra reconhecida apenas em outros recortes de recepção:

Ainsi, entre importation, traduction, interprétation et retraduction, les acteurs de l'internationalisation de l'art moderne furent souvent les créateurs de malentendus esthétiques de taille, dont l'histoire de l'art est encore pétrie. L'importation de l'art moderne a toujours eu des effets induits, non seulement en transformant son milieu de propagation, mais encore en favorisant des contresens productifs causés par des différences de sensibilités et de traditions fortement liées aux identités nationales. [...] la force de l'art d'avant-garde était justement sa pluralité de lectures ${ }^{25}$.

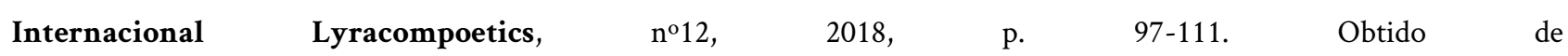

https://www.elyra.org/index.php/elyra/article/view/266.

24 “[...] um profeta só não é estimado em sua própria pátria, entre seus parentes e em sua família." Marcos 6:4; "Eu garanto a vocês: nenhum profeta é bem recebido em sua pátria.” Lucas 4:24. Bíblia sagrada -Edição pastoral. São Paulo: Paulus, 1991, p.1288, 1315.

${ }^{25}$ Traduzo: "Assim, entre importação, tradução, interpretação e retradução, os agentes da internacionalização da arte moderna foram sempre os responsáveis por criar mal-entendidos estéticos de peso que transformaram, assim, a história da arte. A importação da arte moderna sempre teve efeitos indutores, não somente transformando seu meio de propagação, mas favorecendo os contra-senso produtivos causados por diferenças de sensibilidades e tradições fortemente ligadas às identidades nacionais. [...] a força da arte de vanguarda era justamente sua pluralidade de leituras”. V. JOYEUX-PRUNEL, Béatrice. Nul n'est prophète en son pays... ?” ou la logique avant-gardiste - L'internationalisation de la peinture des avant-gardes parisiennes (1855-1914), tese de doutoramento sob orientação de Christophe Charle, Universidade Paris I, 2005, p. 794. 
Viés semelhante ajuda a pensar as vanguardas literárias, estratégias para fomentar campo inovador e autônomo, desfazendo do fluxo artístico vigente no espaço em que se insere o artista. Nesse ponto, o rastreio de recursos e soluções forâneos inquieta demandas do nacional e, em larga medida, a elevação idealizadora do presente afasta o passado numa recusa de tempo e história que moldam o novo espírito desagregador. Nas palavras de Alberto Pimenta, a grande conquista "é o fato de ela [arte] se ter libertado de um cânone considerado eterno, subvertendo assim valores considerados igualmente eternos" ${ }^{\text {26 }}$. Liberdade, porém, não significa, nesse caso, abandono de elementos que subjazem.

Desfazer o abismo entre a concepção proposta pelos artistas modernistas e a visão crítica desse recorte estético requer retorno às fontes e leituras, percebendo tensões instauradas, impasses agudos e proposições estéticas valiosas, fundamentais a esse estudo, conforme sugere a historiadora Tania Regina de Luca:

Bastante reveladora é a predominância dos termos estagnação, esterilidade, superficialidade, vulgaridade, frivolidade, esgotamento para caracterizar não apenas a literatura da época mas o ambiente intelectual e a produção cultural como um todo. Obviamente não se trata de polemizar com as análises centradas na ótica exclusivamente literária, nem tão pouco negar a existência ou subestimar a importância e o significado da vanguarda estética surgida nos anos 20 em prol dos antecessores, mas de submeter o período a uma avaliação que não tome por guia as verdades que o modernismo produziu ${ }^{27}$.

Logo, a análise aprofundada do período de composição das obras parnasianas, bem como da fatura dos poemas, auxilia na tarefa de estabelecer contiguidade em instâncias do diálogo entre os movimentos literários. Evidências na marginália do leitor-escritor Mário de Andrade colaboram no reparo da perspectiva.

Os parnasianos teriam contribuído com o requinte pelo qual a literatura brasileira ansiava, criando a "ilusão de civilização"? Trouxeram questões sensoriais, retomando não apenas resquícios românticos caros ao público, mas dialogando com o impressionismo da pintura europeia? Questões desse porte abrem discussão mais ampla da história em literatura. Ativos na sociedade, presentes nos periódicos e conscientes do que estava sendo produzido, os parnasianos viabilizaram, progressivamente, o caráter institucional da literatura no Brasil, abrindo espaço para um recorte profissional do escritor e a solidificação de um público leitor, como relata com nitidez Emmanuel Santiago:

[...] o parnasianismo triunfante de 1900 não é exatamente o mesmo que assistiu à estreia de Olavo Bilac, anterior à institucionalização da atividade literária no Brasil. Acompanhando cronologicamente a obra de Raimundo Correia, vê-se que, desde Sinfonias (1883) - que traz alguns poemas que poderiam ser considerados ousados pelo público da época - até Poesias (1898), no qual a temática erótica é suprimida, o parnasianismo foi se depurando de uma série de ambivalências até se adequar docilmente ao gosto dominante. Não que essas ambivalências fizessem dele uma escola literária potencialmente contestadora (muito pelo contrário), mas elas o inseriam no clima geral de inconformismo e de sede pelo novo que tomava conta da juventude letrada. Por algum período, o parnasianismo fez parte do caldo cultural em que nossos bacharéis cozinhavam o sonho de uma sociedade moderna e democrática. O que mudou foram menos os princípios estéticos parnasianos, que podiam ser empregados tanto numa poesia mais provocativa quanto numa poesia conformista, do que a situação do escritor na sociedade brasileira. A respeitabilidade à qual Raimundo Correia aspirava em sua maturidade

\footnotetext{
${ }^{26}$ PIMENTA, Alberto. O silêncio dos poetas. Portugal: Livros Cotovia, 2003, p. 55.

${ }^{27}$ LUCA, Tania Regina de. A revista do Brasil: um diagnóstico para a (N)ação. São Paulo: Editora da UNESP, 1999 , p. 23.
} 
não era apenas uma idiossincrasia sua; era, também, uma exigência oriunda das novas circunstâncias sociais que cercavam a atividade literária. A maioria dos intelectuais que não se adequaram a esse contexto acabou marginalizada. ${ }^{28}$

O olhar parnasiano propõe-se moderno ou anacrônico no longo período em que se desenvolve e estabelece? Decerto, redimensionar seu valor histórico e restituir estudos das práticas versificatórias evita incidir em formatações críticas contrárias ao parnasianismo, elencando unicamente características pasteurizadas a fim de salientar as diferenças em relação à produção modernista. Ou, como bem define Antonio Secchin:

O ponto de partida para refletirmos sobre o Parnasianismo é o seguinte: o movimento costuma ser estigmatizado por não ser o que ele não se propôs a ser. Existem contra ele críticas dessa natureza: o parnasianismo não tem a carga emotiva do romantismo, então o parnasianismo, nesse viés, é um romantismo desfalcado de emoção; o parnasianismo não tem a complexidade do simbolismo; o parnasianismo não carrega a carga irônica de nosso primeiro modernismo. Observe-se, em todas essas condenações, uma espécie de definição negativa, de tentar dizer que o movimento é aquilo que deixou de ser. ${ }^{29}$

Mário leitor convida a outra perspectiva de aproveitamento da matéria poética, franqueando diálogos possíveis: valoração das técnicas, aprendizado sem subserviência, aplicação de recursos estéticos, exercícios de escrita e rupturas críticas. O jovem em formação abre-se à dialética que será uma constante em seus projetos, as contradições como espelho do Brasil que lhe interessa - erudito e popular, formal e prosódico, da norma e exceção. O espírito desagregador ligado ao impulso libertário apostolado pelas vanguardas vai de encontro ao estudo formal dos parnasianos, leitura que propõe deslocamentos. O êxito moderno, entretanto, coincide justamente com a experimentação constante; melhor dizendo, moderno porque contempla também o passado, aberto às percepções críticas e artísticas.

Em 1925, na criação do periódico mineiro A Revista, espaço de mescla entre estilos e gerações, como detalha Camila Russo de Almeida Spagnoli ${ }^{30}$, Mário de Andrade, ao lado de Manuel Bandeira, adverte Drummond e, em carta, enfatiza a importância de certa diplomacia no tom do jornal, desvio do impacto provocativo proposto anteriormente, nos primeiros tempos modernistas:

Aconselho diplomacia nas relações com o passadismo mineiro. Aproximação e sova por meio da prosa raciocinadora. Porrada só como revide ${ }^{31}$.

[...] botem bem misturados o modernismo bonito de vocês com o passadismo dos outros. Misturem o mais possível. É o único meio da gente fazer do público terra-caída amazonense. É

\footnotetext{
${ }^{28}$ SANTIAGO, Emmanuel. A musa de espartilho: o erotismo na poesia parnasiana brasileira. Op. cit., p. 168.

${ }^{29}$ SECCHIN, Antonio Carlos. Presença do Parnaso In: JUNQUEIRA, Ivan (Org.). Escolas literárias no Brasil. Op. cit., p. 491.

${ }^{30}$ SPAGNOLI, Camila. Uma vida nada ociosa: Godofredo Rangel na Revista do Brasil (1917-1924), tese de doutoramento sob orientação de Marcos Antonio de Moraes, FFLCH-USP, 2020.

${ }^{31}$ Carta de Manuel Bandeira a Carlos Drummond de Andrade, 31 ago. 1925. Apud DOYLE, Plínio. História de revistas e jornais literários. A Revista (edição fac-similar). São Paulo: Metal Leve, 1978. V. MARQUES, Ivan. Modernismo em revista: estética e ideologia nos periódicos dos anos 1920. Rio de Janeiro: Casa da Palavra, 2013, p. 51-52.
} 
isso que é preciso. Ele pensa que está firme no passadismo e de sopetão vai indo de cambulhada, não sabe e está se acostumando com vocês ${ }^{32}$.

A mistura forçosa das estéticas, que se mostra também como estratégia para angariar a atenção do públicoleitor, recebe acertada definição de Ivan Marques, em estudo sobre as revistas do modernismo: "Assim eram os rapazes de Belo Horizonte: vanguardistas, mas sobretudo diplomáticos; modernistas, porém acadêmicos" ${ }^{\text {"33 }}$. A relativização dificultosa do passado, nesses escritores, insurge como entrave no estabelecimento de novos paradigmas. No entanto, a nuance de manifesto e a disputa do meio criador não podem corromper a análise severa, a crítica, sobretudo após o distanciamento temporal.

Acompanhar o crivo do leitor-crítico, mais tarde, contribui para perceber certas infiltrações em seu aparato teórico. Em 1939, “A poesia em pânico”, ensaio de Mário de Andrade sobre o livro de Murilo Mendes do mesmo título, apresenta a obra sem se desviar da perspectiva estrutural dos poemas e do trabalho com a sonoridade, lição aprendida e passada à frente:

Esta é a observação técnica que o livro impõe. Ele se apresenta cheio de pequenas falhas técnicas provando despreocupação pelo artesanato. [...] Os elementos da perfeição técnica, os encantos da beleza formal estão muito abandonados. O verso-livre é correto mas monótono, cortado exclusivamente pelas pausas das frases e das ideias. [...] Às vezes há uma velocidade irrespirável. As frases não expiram: acabam. [...] Tudo isso é belo, vigorosíssimo, mas não há descansos, não há pousos, isto é, não há combinação. [...] As pequenas falhas de habilidade rítmica são frequentes, como aquela preposição 'de' ('preciso de vomitar') que torna capenga um verso de "O Exilado". De muita importância é a desatenção rítmica com que Murilo Mendes termina às vezes os seus poemas. ${ }^{34}$

Mário critica o poeta moderno pela ausência de ritmo. O ensaio nos encaminha diretamente à marginália do leitor no livro de Murilo Mendes, abertura proposta na tese de doutoramento de Aline Novais de Almeida ${ }^{35}$ com descrição de notas valiosas que se coadunam às incursões do estudioso. Vale observar o destaque no poema "O exilado", a grafite, da preposição "de" em "Preciso de vomitar a vida em sangue". O comentário crítico "falta de ritmo", na sequência, indica o leitor inconformado com a perda de um decassílabo, pois o verso, como se apresenta, conta onze sílabas poéticas. Volta a atenção para a sonoridade, outra vez mais, em "Poema poético", no mesmo exemplar. Ali, insere a apreciação "mau ritmo". Os versos de Murilo Mendes, poeta de extravasamento, refratário, colidem com o matiz técnico do olhar iluminador de Mário de Andrade e seu desejo de artesanato.

Escudado na leitura parnasiana, versado em manuais e tratados, colecionador de dicionários, ecoa em Mário de Andrade o apuro aprendido nestas lições. Quase como se restasse latente o preceito estudado na Arte de fazer versos, de Osório Duque Estrada: "No emprego de qualquer figura que autorize alterações de palavra, é preciso

\footnotetext{
${ }^{32}$ Carta de Mário de Andrade a Carlos Drummond de Andrade, 23 ago. 1925. Ibidem.

${ }^{33}$ MARQUES, Ivan. Modernismo em revista: estética e ideologia nos periódicos dos anos 1920, Op. cit., p. 57.

${ }^{34}$ ANDRADE, Mário de. A poesia em pânico In: Diário de notícias, Rio de Janeiro, 9 abr. 1939. V. SÁ, Marina Damasceno de. O empalhador de passarinho, de Mário de Andrade: edição de texto fiel e anotado, dissertação de mestrado sob orientação de Telê Ancona Lopez, FFLCH-USP, 2013, p. 147.

35 AlmeidA, Aline Novais de. Manequim de pássaros: ritmo, corpo e metamorfose em Murilo Mendes, tese de doutoramento sob orientação de Eliane Robert Moraes, FFLCH-USP, 2019, p. 96.
} 
haver o máximo escrúpulo para não cair o neófito em vícios e corruptelas deformadoras do nosso idioma” ${ }^{36}$. Essa leitura formadora esculpe parcelas do crítico e do poeta; aparece nos termos de comparação, nas referências de estudo, no assunto de poemas retomados, na coerência rítmica acolhida como base.

Assim, é preciso converter a imagem negativa que insiste em afastar os parnasianos do campo de discussão literária, entoando o lema do primeiro tempo modernista, como adverte Ivan Teixeira:

Os novos escritores conseguiram impor-se. Mais do que isso, transmitiram às novas gerações seu horror literário pelo Parnasianismo. [...] todos previamente recusados, sob pretexto de que são frios, mecânicos, superficiais, formalistas, retrógrados, previsíveis, burgueses, etc. Repetem-se hoje os estereótipos criados pela estratégia do combate modernista. ${ }^{37}$

O imaginário da Semana de 1922 não pode obscurecer uma arte fundamentada em características próprias, de relevância no espectro nacional e partícipe de uma linha de produções artística que se aproximam e distanciam. Para tanto, uma leitura que contemple as obras, os poetas e o contexto histórico parnasiano se anuncia mais integral e produtiva. Persiste Ivan Teixeira:

Talvez seja mais atual ler o Parnasianismo como se lêem os demais estilos do passado, isto é, com relativismo histórico, não em termos de adesão ou recusa estética. Projetar no passado convicções adquiridas no presente pode gerar anacronismos incompatíveis com a boa inteligência dos textos, além de funcionar como armadilha para possíveis preconceitos. ${ }^{38}$

Esboços do leitor-poeta Mário de Andrade nas páginas de Machado de Assis e Vicente de Carvalho, chaves de ouro selecionadas como predileção por finais prosaicos, temas colhidos em Alberto de Oliveira e Baptista Cepellos, o apreço pelos instantes descritivos, onomatopeias e enumeração, o rascunho e a triagem de rudimentos para tecer críticas, assim como os verbalismos e vocábulos de sensível beleza perpassam os olhos atentos do poeta e do crítico em formação que revisita seus exemplares parnasianos ao longo de sua trajetória. Esses elementos reverberam em sua obra de muitas formas, ganhando aderência mesmo nas infrutíferas tentativas de se esquivar dos aprendizados latentes. Em 1924, na poética A escrava que não é Isaura, propõe a orientação acertada para o trato da matéria poética, lição incorrigível: "Não me incomoda mais a existência dos tolos e cá muito em segredo, rapazes, acho que um poeta modernista e um parnasiano todos nos equivalemos e equiparamos" ${ }^{39}$.

\section{Referências}

AlmeIDA, Aline Novais de. Manequim de pássaros: ritmo, corpo e metamorfose em Murilo Mendes. Tese de doutoramento em Literatura Brasileira, sob orientação de Eliane Robert Moraes, FFLCH-USP, 2019.

\footnotetext{
${ }^{36}$ EstradA, Joaquim Osório Duque. A arte de fazer versos. Rio de Janeiro: Francisco Alves, 1914, p. 71-71.

37 TeIXEIRA, Ivan. Em defesa da poesia (bilaquiana). Introdução à organização de Poesias, de Olavo Bilac. São Paulo: Martins Fontes, 1996, p. XII.

${ }^{38}$ Ibidem, p. XXX.

39 ANDRADE, Mário de. A escrava que não é Isaura - Discurso sobre algumas tendências da poesia modernista In:

Obra Imatura, Ed.cit., p. 334.
} 
ANDRADE, Carlos Drummond de. T’aí!. In: Amor nenhum dispensa uma gota de ácido - Escritos de Carlos

Drummond de Andrade sobre Machado de Assis. Organização e apresentação de Hélio de Seixas Guimarães. São Paulo: Três Estrelas, 2019.

ANDRADE, Mário de. Obra Imatura. Ed. coordenada por Telê Ancona Lopez e texto estabelecido por Aline Nogueira Marques. Rio de Janeiro: Nova Fronteira, 2009.

. Carta-aberta a Alberto de Oliveira In: Lopez, Telê Ancona (org). Carta-aberta a Alberto de Oliveira - resposta a Mário de Andrade. Revista do Instituto de Estudos Brasileiros, nº 23. São Paulo: IEBUSP, 1981.

1925 - Assim falou o Papa do futurismo. In: Lopez, Telê Ancona (org.). Mário de Andrade: entrevistas e depoimentos. São Paulo: T. A. Queiroz, 1983.

Poesias completas v. 1-2. Edição preparada por Tatiana Longo Figueiredo e Telê Ancona

Lopez. São Paulo: Nova Fronteira, 2013.

A poesia em pânico In: Diário de notícias, Rio de Janeiro, 9 abr. 1939. In: Sá, Marina

Damasceno de. O empalhador de passarinho, de Mário de Andrade: edição de texto fiel e anotado, dissertação de mestrado em Literatura Brasileira sob orientação de Telê Ancona Lopez, FFLCH-USP, 2013.

ANTONIO CANDIDO. Formação da literatura brasileira. 12a Ed. São Paulo/ Rio de Janeiro: Ouro sobre Azul, 2009.

AMARAL, Amadeu. Espumas: versos. São Paulo: Editora d’A Cigarra, 1917.

BILAC, Olavo. BILAC, Olavo. Tarde. Rio de Janeiro/ São Paulo/ Belo Horizonte: Livraria Francisco Alves, 1919. Poesias. 4a. ed. Rio de Janeiro/ São Paulo/ Belo Horizonte: Livraria Francisco Alves, 1909.

COSTA, Firmino. Vocabulário analógico. São Paulo: Melhoramentos, 1933.

EstradA, Joaquim Osório Duque. A arte de fazer versos. Rio de Janeiro: Francisco Alves, 1914.

Gomes, Eugênio. Raimundo Correia e o idealismo horaciano In: Visões e revisões, Rio de Janeiro: Instituto Nacional do Livro, 1958.

JoyeuX-Prunel, Béatrice. Nul n'est prophète en son pays...?” ou la logique avant-gardiste L'internationalisation de la peinture des avant-gardes parisiennes (1855-1914), tese de doutoramento sob orientação de Christophe Charle, Universidade Paris I, 2005.

KIMORI, Ligia. Pauliceia parnasiana: Mário de Andrade leitor e poeta nas margens de Baptista Cepellos. ELyra:

Revista Da Rede Internacional Lyracompoetics, $\mathrm{n}^{\circ} 12$, 2018, p. 97-111. Obtido de https://www.elyra.org/index.php/elyra/article/view/266.

LOPEZ, Telê Ancona. "Mário de Andrade leitor e escritor: matrizes e marginália”. Guavira Letras, Três Lagoas/ MS, no 23, p. 14-33, jul/ dez 2016

LUCA, Tania Regina de. A revista do Brasil: um diagnóstico para a (N)ação. São Paulo: Editora da UNESP, 1999.

MACHADO DE AsSIS. Poesias completas. Rio de Janeiro/ Paris: Livraria Garnier, 1902. 
MARQUES, Ivan. Modernismo em revista: estética e ideologia nos periódicos dos anos 1920. Rio de Janeiro: Casa da Palavra, 2013.

OliVEIRA, Alberto de. O culto da forma na poesia brasileira In: Conferências 1914-1915. São Paulo: Typographia Levi, 1916, p. 273. Conferência realizada em 10 de novembro de 1915.

. Poesias $3^{\text {a }}$ série (Sol de verão, Céo nocturno, Alma das cousas, Sala de baile, Rimas varias,

No seio do cosmos, Natalia). Rio de Janeiro/ São Paulo/ Belo Horizonte: Livraria Francisco Alves e cia, 1913.

PIMENTA, Alberto. O silêncio dos poetas. Portugal: Livros Cotovia, 2003.

RAMOS, Péricles Eugênio da Silva. A renovação parnasiana na poesia In: COUTINHO, Afrânio (Org.). A literatura no Brasil, vol. 4: era realista, era de transição. São Paulo: Global, 2004.

SANTIAGO, Emmanuel. A musa de espartilho: o erotismo na poesia parnasiana brasileira. Tese de doutoramento sob orientação de Vagner Camilo, FFLCH-USP, 2016.

SECCHIN, Antonio Carlos. Presença do Parnaso In: Junqueira, Ivan (org.). Escolas literárias no Brasil. Rio de Janeiro: Academia Brasileira de Letras, 2004.

SPAGNOLI, Camila. Uma vida nada ociosa: Godofredo Rangel na Revista do Brasil (1917-1924), tese de doutoramento em Literatura Brasileira sob orientação de Marcos Antonio de Moraes, FFLCH-USP, 2020.

TeIXEIRA, Ivan. Em defesa da poesia (bilaquiana). Introdução à organização de Poesias, de Olavo Bilac. São Paulo: Martins Fontes, 1996.

Recebido em: 14 de setembro de 2020 Aceito em: 22 de setembro de 2020 